\title{
FORMAÇÃO CONTINUADA EM EDUCAÇÃO DE JOVENS, ADULTOS E IDOSOS: aspectos legais e implementação de ações direcionadas aos professores da educação básica
}

\author{
CONTINUED EDUCATION FOR TEACHERS' IN THE PROGRAM FOR \\ EDUCATION OF YOUNG, ADULTS AND ELDERLY STUDENTS: legal \\ aspects and implementation of actions directed basic education teachers
}

\author{
FORMACIÓN CONTINUA EN EDUCACIÓN DE JÓVENES, \\ ADULTOS Y ANCIANOS: aspectos legales y implementación de \\ acciones dirigidas a los profesores de educación básica
}

\author{
Diego Rodrigo Pereira \\ Professor do Instituto Federal de Educação, \\ Ciência e Tecnologia do Maranhão (IFMA). \\ Mestrando do Programa de Pós-Graduaçãoem Educação \\ da Universidade Federal do Maranhão (UFMA). São Luís-MA, Brasil. \\ diegoantropologo@hotmail.com \\ Francisca das Chagas Silva Lima \\ Professora Doutora do Programa de Pós-Graduação/ \\ Mestrado em Educação e do Departamento de Educação II \\ da Universidade Federal do Maranhão (UFMA). São Luís-MA, Brasil. \\ fransluma@bol.com.br
}

\begin{abstract}
Resumo: Este artigo analisa as políticas públicas educacionais que se referem às orientações sobre formação docente, na expectativa de identificar os avanços da formação continuada dos professores da educação básica que atuam na Educação de Jovens, Adultos e Idosos dos estabelecimentos de ensino da rede pública estadual do Maranhão. Dada a necessidade de elaboração de estratégias diferenciadas nessa modalidade de ensino, a formação continuada de educadores de jovens, adultos e idosos representa uma alternativa para atender à realidade e aos interesses dos educandos. Este estudo caracterizase como uma pesquisa qualitativa e quantitativa, que utiliza como procedimentos metodológicos a pesquisa bibliográfica e documental e uma investigação no âmbito da Secretaria de Estado de Educação do Maranhão, com técnicos desse órgão, por meio de entrevistas e levantamento de dados estatísticos que, depois de tabulados, analisados e qualificados respaldaram a elaboração do presente artigo. Nas considerações finais, apresentamos alguns elementos decorrentes da pesquisa realizada, os quais nos permitem apontar que, no estado do Maranhão, as ações de formação continuada nesse campo educacional ainda estão longe de atingir todos os professores que atuam nessa modalidade de ensino, inviabilizando o adequado aperfeiçoamento desses profissionais. A implementação das ações esbarra na descontinuidade das políticas públicas, na falta de orçamento e nas mudanças frequentes na coordenação das ações de Educação de Jovens, Adultos e Idosos no âmbito da referida instituição sem qualquer aproveitamento ou aperfeiçoamento do que já havia sido iniciado.
\end{abstract}

Palavras-chave: Formação. Educação. Professores.

\begin{abstract}
This article analyses the educational public politics related to the teachers' training, in expectation to identify the advances in the continued training program to basic education teachers who work with the Education of Young, Adults and Elderly at the public establishment of the State of Maranhão. To give the necessity of implementing different strategies in this kind of teaching, continued training of teachers of youngsters, adults and the elderly represents an alternative to attain to the reality and the interests of the students. This study is characterized as a qualitative and quantitative research, it utilizes as methodological procedures literature and documentary research and investigation in scope the Government department of Education of the State of Maranhão, with technicians from this institution, by means of interviews and surveys which, after being tabled, analyzed and qualified they reinforce the production of this article. In the conclusion final we present some elements to result from the research accomplished, which allow us point out that in the state of Maranhão, the actions for continued training in this educational field are still a long way to reach all teachers who work in this kind of teaching, hindering the adequate improvement of teachers. The implementation of actions to bump continuation of public politics, apart from frequent changes in the coordination of actions for Education of Young, Adults and Elderly in the institution itself which contributes to the non-continuation or change of government policies, without any profit or improvement of what had already been started.
\end{abstract}

Keywords: Training. Education. Teachers.

Artigo recebido em setembro de 2017
Aprovado em novembro de 2017

Cad. Pesq., São Luís, v. 24, n. 3, set./dez. 2017 
Resumen: Este artículo analiza las políticas públicas educativas que hacen referencia a las directrices sobre la formación del profesorado, con la esperanza de identificar los progresos de la educación continua de los profesores de la enseñanza de educación primaria que trabajan en la Educación de Jóvenes, Adultos y Ancianos de las escuelas públicas del Estado de Maranhão. Con la necesidad de preparar estrategias diferentes en ese modo de la educación, la formación continua de profesores de los jóvenes, adultos y ancianos es una alternativa para ayudar en la realidad y en los intereses de eses estudiantes. Ese estudio caracterizase como una investigación cualitativa y cuantitativa, utilizando procedimientos metodológicos como a investigación de la literatura y documental y la investigación en el Departamento de Estado de Educación de Maranhão, con su proprio cuerpo técnico, a través de entrevistas y estadísticas, que después de tabulados, analizados y calificados apoyó la preparación de este artículo. En las consideraciones finales presentamos algunos resultados de el estudio hecho que nos permiten señalar que, en el estado de Maranhão, las acciones de formación continua en ese campo de la educación, aún están lejos de llegar a todos los profesores involucrado en este tipo de educación, lo que hace imposible el desarrollo adecuado de los maestros. La realización de acciones choca con la discontinuidad de las políticas, en la falta de presupuesto, además de los frecuentes cambios en la coordinación de las acciones de la Educación de Jóvenes, Adultos y Ancianos en el contexto de la institución sin ningún tipo de recuperación o mejora de lo que ya se había iniciado.

Palabras clave: Formación. Educación. Profesores.

\section{INTRODUÇÃO}

A formação inicial e continuada dos professores que atuam na educação básica é estrategicamente importante para tornar a aprendizagem escolar uma experiência estimulante. Desde a Constituição Federal de 1988 e a promulgação da Lei de Diretrizes e Bases da Educação Nacional (LDB), Lei n 9.394/96, até agora, o Estado brasileiro vem adotando medidas para garantir a formação adequada dos professores do sistema público de ensino, colaborando para a melhoria da qualidade da educação escolar do País.

Uma das principais mudanças educacionais introduzidas pela LDB de 1996 foi a exigência de formação docente em nível superior, em curso de licenciatura, como formação mínima para atuar no magistério da educação básica, sendo assegurada a formação em nível médio na modalidade Normal para atuar na educação infantil e nas quatro primeiras séries do ensino fundamental. Além disso, também ficou definido o aperfeiçoamento profissional continuado para valorização dos profissionais da Educação.

Para atender às necessidades educacionais, o aperfeiçoamento profissional continuado voltou a ser discutido nas alterações realizadas posteriormente na LDB por meio da Lei $n^{\circ} 12.014$, de 06 de agosto de 2009 , dispondo sobre a capacitação em serviço com a finalidade de "atender às especificidades do exercício de suas atividades, bem como aos objetivos das diferentes etapas e modalidades da educação básica" (BRASIL, 2009b, p. 1).

No início de 2009, no governo do então Presidente Luís Inácio Lula da Silva, o Decreto $n^{\circ}$ 6.755 instituiu a Política Nacional de Formação de Profissionais do Magistério da Educação Básica, disciplinando a atuação da Coordenação de Aperfeiçoamento de Pessoal de Nível Superior (CAPES) no fomento de programas de formação inicial e continuada dos profissionais do magistério em âmbito nacional (BRASIL, 2009a). Com as mudanças na LDB e a adoção de uma política nacional de formação docente, o País passou a dispor de novas diretrizes de recomendação para uma formação docente adequada, abrangendo as diferentes modalidades da educação básica em que atuam os professores.

Posteriormente, subsidiada na Política Nacional de Formação de Profissionais do Magistério da Educação Básica, foi instituída a Portaria de n 883/2009 para disciplinar o funcionamento dos Fóruns Estaduais Permanentes de Apoio à Formação Docente, criados para organizar a formação inicial e continuada dos professores das redes públicas da educação básica em âmbito estadual (BRASIL, 2009c).

Com a aprovação do atual Plano Nacional de Educação (PNE), Lei n 13.005/14, a formação inicial e continuada tornou-se meta nacional para valorização dos profissionais da educação na próxima década, ou seja, no decênio 2014-2024, buscando um quadro de professores comprometidos com a boa qualidade do ensino referenciada na Constituição Federal de 1988.

A respeito das metas do PNE 2014, que focalizam a formação inicial e continuada de professores, destaca-se inicialmente a $n^{\circ} 15$ que prescreve que todos os professores da educação básica possuam formação específica de nível superior, obtido em curso de licenciatura na área de 
conhecimento em que atuam, por meio de política específica dentro do prazo de um ano de vigência do PNE (BRASIL, 2014). Essa meta, em outras palavras, reitera a formação exigida anteriormente na LDB de 1996 para todos os professores que atuam na educação básica.

A meta $n^{\circ} 16$ do PNE 2014 recomenda investimentos para que todos os profissionais da educação básica possuam formação continuada em sua área de atuação (BRASIL, 2014), também reforçando os preceitos da LDB de 1996, que instituiu a capacitação em serviço como uma forma de atendimento das especificidades diárias que ocorrem no ambiente escolar.

Da mesma forma, o atual Plano Estadual de Educação do Estado do Maranhão (PEE/MA), Lei $n^{0}$ 10.099/14, enfatiza a criação de diretrizes estaduais para organização de uma política de formação inicial e continuada de professores (MARANHÃO, 2014), fomentando a formação dos professores no decênio 2014-2024, dentro das especificidades de cada etapa e modalidade educacional.

Nessa perspectiva, foi aprovada pelo Conselho Nacional de Educação (CNE) a Resolução ${ }^{\circ}$ 2, de $1^{\circ}$ de julho de 2015, definindo as Diretrizes Curriculares Nacionais para a Formação Inicial e Continuada dos Profissionais do Magistério para a Educação Básica, e regulamentado pelo Ministério da Educação (MEC) o Decreto $n^{\circ}$ 8.752, de 9 de maio de 2016, que dispôs sobre a nova Política Nacional de Formação dos Profissionais da Educação Básica. Tais dispositivos legais reforçaram a formação adequada dos professores que atuam nesse nível educacional.

Do ponto de vista específico, na Educação de Jovens, Adultos e Idosos (EJAI) ${ }^{1}$, as Diretrizes Curriculares Nacionais para a Educação de Jovens e Adultos estabelece a organização de cursos de formação inicial e continuada dos professores que atuarão nessa modalidade de ensino. Essa formação deverá ser realizada em ambiente institucional adequado e apoiada em investigações de problemas dessa modalidade de educação, em práticas educativas que articulem teoria e prática e com a utilização de métodos e técnicas que contemplem códigos e linguagens apropriados às suas situações específicas de aprendizagem (BRASIL, 2000).

O documento Marco da Ação de Belém/2009, resultado do esforço que a Sexta Conferência Internacional de Educação de Adultos (VI CONFINTEA) empreendeu pela melhoria do acesso aos processos de educação e aprendizagem de jovens, adultos e idosos, também assumiu o compromisso de planejar e implementar a formação inicial e continuada dos educadores, bem como melhorar as condições de trabalho desses profissionais (BRASIL, 2010).

Diante dessas considerações iniciais, interessa saber, nesta investigação, qual a atenção que vem sendo dada à formação dos professores que atuam na EJAI. Considerando que a formação inicial não contempla as competências e habilidades necessárias à atuação docente na área de EJAI, a pesquisa tem como foco a concepção de formação continuada contemplada nas ações/cursos que objetivam proporcionar o aperfeiçoamento e atualização dos fundamentos teórico-metodológicos dos professores que atuam nessa modalidade de ensino.

Nesse sentido, a presente pesquisa teve como objetivo analisar os atuais instrumentos legais que recomendam e normatizam a formação continuada dos professores da educação básica, identificando as ações e os cursos de formação continuada oferecidos aos professores que atuam na EJAI das escolas de Ensino Fundamental e Médio da Rede Pública Estadual do Maranhão, apontando as possíveis implicações da realização ou não dessas iniciativas nas práticas dos professores em sala de aula e seus reflexos na aprendizagem dos alunos.

Trata-se de uma pesquisa qualitativa e quantitativa, de cunho crítico analítico das situações que envolvem a formação dos professores que atuam na EJAI. Como procedimentos metodológicos foi realizada uma pesquisa bibliográfica e documental contemplando livros, artigos de periódicos, dissertações, leis, decretos, resoluções, pareceres e relatórios técnicos com o intuito de recolher informações e conhecimentos necessários a compreensão do problema de investigação.

$\mathrm{O}$ instrumento de pesquisa utilizado para coleta de dados foi o roteiro de entrevista semiestruturada aplicado aos técnicos que coordenam as ações dessa modalidade de ensino na Supervisão de Educação de Jovens e Adultos (SUPEJA), na Assessoria de Formação Inicial e Continuada e na Superintendência de Estatística, ambas da Secretaria de Estado da Educação do Maranhão (SEDUC/MA).

\footnotetext{
1 Os documentos finais da $2^{\text {a }}$ Conferência Nacional de Educação - CONAE 2014 e o PNE de 2014 concebem a permanência e a continuidade dos estudos ao segmento jovem, adulto e idoso na modalidade Educação de Jovens e Adultos (EJA). O PEE/MA de 2014 utiliza a nomenclatura Educação de Jovens, Adultos e Idosos (EJAI) para se referir à modalidade da educação básica que atende ao mesmo segmento. Faremos uso da sigla EJAI no decorrer do artigo, por entendermos que a universalização do direito à educação e a sua oferta pública como porta de entrada para escolarização das pessoas ao longo de toda a vida também incluem os idosos.
} 
Desse modo, a investigação, a partir dos resultados alcançados, apresenta o gerenciamento das políticas educacionais e algumas discussões pertinentes ao ambiente escolar e entre os profissionais da educação do estado do Maranhão, de modo que as políticas de formação inicial e continuada de professores da educação básica possam ser avaliadas com vistas à sua continuidade, reformulação e até mesmo descontinuidade.

\section{ORIENTAÇÕES DOS DISPOSITIVOS LEGAIS}

O Estado brasileiro é historicamente marcado por iniciativas educacionais com o intuito de combater as desigualdades sociais existentes no País. No que se refere ao campo de educação para jovens e adultos, destacamos que na década de 1980 ocorreu uma oferta pública bastante restrita de ações a esse segmento. Com a promulgação da Constituição Federal de 1988, a educação passou a ser um direito de todos e dever do Estado e da família, estabelecendo como responsabilidade do Estado a oferta do ensino fundamental obrigatório e gratuito, inclusive aos que a ele não tiveram acesso na idade própria.

A partir de então, começaram a ser adotadas políticas efetivas para garantir a oferta da educação básica à população brasileira dentro dos princípios de pleno desenvolvimento da pessoa, com vistas a seu preparo para o exercício da cidadania e sua qualificação para o trabalho (BRASIL, 1988). A elevação da EJAI a uma modalidade educacional na nova LDB contribuiu para o aumento da oferta de ações à população jovem, adulta e idosa, além de, consequentemente, colaborar para diminuir o número de pessoas que nunca tiveram a oportunidade de ingressar na escola e nela permanecer, ou daquelas que dela se evadiram e não puderam concluir os estudos na idade própria. Com isso, a EJAI foi contemplada na legislação como direito e se consolidou como uma modalidade de ensino.

Em relação a esse período de novas conquistas do direito à educação, que atendesse a um segmento anteriormente não contemplado nos instrumentos legais do Estado brasileiro, Carvalho (2011, p. 92) coloca que, "nos anos de 1990, um cenário diferente do que ocorrera nos anos 1980 se delineia para a EJA". Sarmento (2012, p. 9) aponta que "há um esforço visível, nas últimas décadas, para universalizar a educação básica no Brasil, garantindo padrões de qualidade equivalentes aos dos países considerados desenvolvidos".

Nos primeiros anos da década de 2000, que envolvem os governos do Presidente Luís Inácio Lula da Silva, por exemplo, várias inciativas dessa modalidade de ensino se fortaleceram, inclusive por conta da criação do Fundo de Manutenção e Desenvolvimento da Educação Básica e de Valorização dos Profissionais da Educação (FUNDEB), por meio da Emenda Constitucional n 53/2006, e que foi regulamentado pela Lei $n^{\circ} 11.494 / 2007$ e pelo Decreto $n^{\circ} 6.253 / 2007$, que teria alcance na EJAI anteriormente prejudicada no âmbito do Fundo de Manutenção e Desenvolvimento do Ensino Fundamental e de Valorização do Magistério (FUNDEF). Convém ressaltar que diferentemente do FUNDEF, o FUNDEB contempla o teto de $15 \%$ dos seus recursos para financiamento das ações na EJAI.

Nos anos seguintes, os avanços para combater as desigualdades na educação brasileira continuaram ocorrendo mediante novas políticas que destinavam recursos para o enfrentamento dos problemas educacionais. No entanto, conforme compreende Osterne (2014), a maioria das políticas sociais tem se caracterizado ou se caracterizavam por um conjunto de ações desenvolvidas de maneira desarticulada pelas instituições responsáveis pela implementação de políticas setoriais aliadas ao desperdício de recursos oriundos de uma diversidade não planejada de fontes.

Essa realidade evidencia que, embora estabelecidos vários preceitos legais que garantam a oferta pública da EJAI, as iniciativas desenvolvidas ainda não são suficientes para combater as desigualdades sociais que caracterizam o País. O Maranhão, conforme sublinha Guerra, Pochmann e Silva (2014) no Atlas da Exclusão Social no Brasil, encontra-se entre os três estados da federação com os piores índices de exclusão na dimensão escolaridade e um dos três piores no quesito analfabetismo, no índice de exclusão social, evidenciados na composição dos índices da exclusão para o ano de 2010.

Percebemos que o Maranhão ainda se encontra bastante distante do patamar de ensinoaprendizagem essencial para que possa ser indicada a melhoria da qualidade da educação. Nos últimos anos, problemas como a falta de escolas, as péssimas condições de infraestrutura escolar, a falta de professores, a necessidade de recursos didáticos e o descaso com a merenda escolar têm sido 
algumas características da educação pública no Estado brasileiro. Esses e outros problemas acabam ocasionando o desinteresse das pessoas em buscar a escola pública para iniciar ou continuar os estudos, distanciando cada vez mais a tão sonhada redução dos índices de desigualdade social por meio da educação escolar. No entanto, embora esses problemas sejam notórios, um dos principais aspectos indicados pelas avaliações nacionais para justificar os problemas de baixo desempenho educacional é o pedagógico, ou seja, a aula do professor.

Consubstanciados no referencial bibliográfico de autores como Imbernón (2010), Scarpato (2004), Pereira (2006) e Soares (2006), para quem "a garantia das condições de acesso e permanência passa pela qualidade da educação da qual a formação do educador é componente" (SOARES, 2006, p. 284); e ainda no disposto nos instrumentos legais, tais como: o PNE 2014-2024, o PEE/MA 2014-2024, as Diretrizes Curriculares Nacionais para a Formação Inicial e Continuada dos Profissionais do Magistério para a Educação Básica, a Política Nacional de Formação dos Profissionais da Educação Básica, as Diretrizes Curriculares Nacionais para a Educação de Jovens e Adultos e o Documento Marco da Ação de Belém/2009 (VI CONFINTEA) dentre outros dispositivos legais, inferimos que a formação inicial e continuada dos professores é uma atividade indispensável para a melhoria dos indicadores educacionais do estado do Maranhão.

De acordo com o disposto na Constituição Federal de 1988 e na LDB de 1996, o Estado brasileiro, nos últimos anos, passou a realizar novos investimentos na formação inicial e continuada dos professores da educação básica, compreendida como uma ação indispensável a uma prática docente que estimule os alunos a frequentar a escola e a querer nela permanecer, construindo conhecimentos e desenvolvendo aprendizagens que contribuam para o seu êxito na sociedade. Ao pensar a formação docente dentro da perspectiva da EJAI, Rios (2011, p. 60) destaca que, "[...] constata-se a necessidade de uma prática pedagógica que contemple a realidade e os interesses do educando jovem e adulto. E isso implica formação adequada por parte do corpo docente".

Uma das premissas da Política Nacional de Formação dos Profissionais da Educação Básica estabelece a articulação entre formação inicial e continuada (BRASIL, 2016). Ainda, as Diretrizes Curriculares Nacionais para EJAI sinalizam a formação inicial e continuada dos professores que atuam nessa modalidade de ensino com base nas "diretrizes curriculares nacionais para o ensino fundamental e para o ensino médio” (BRASIL, 2000, p. 3). Porém, conforme destaca Pereira (2006), não existe integração entre a Licenciatura e a realidade onde os licenciados atuarão, constituindo-se em um velho problema enfrentado pelos cursos de formação inicial de professores.

Ao fazermos uma análise dos cursos de licenciatura oferecidos pelas Instituições de Ensino Superior (IES), observamos que não é contemplada a construção de competências e habilidades para atuar na EJAI, salvo os Cursos de Pedagogia, cujas diretrizes definem um profissional capacitado nas metodologias para atuar nessa modalidade de ensino. A realidade das outras licenciaturas é a formação de um professor sem o preparo adequado para se inserir no mercado de trabalho no campo da EJAI. As IES são responsáveis por essa formação específica, devendo inserir conteúdos que contemplem conhecimentos sobre a EJAI, principalmente no que concerne à questão da iniciação ou retomada profissional das pessoas jovens, adultas e idosas, nos Projetos Pedagógicos e Matrizes Curriculares de todas as licenciaturas, até como estratégia para prevenir a evasão escolar.

Em consequência disso, como podemos pensar uma formação continuada, se a própria formação inicial não combina teoria e prática? Podemos mencionar, por exemplo, a formação continuada dos professores da EJAl, se eles não dispõem de formação inicial nessa área. Ela será continuada a partir de quê? Em quais aspectos?

Diante das lacunas deixadas nos cursos de licenciatura, se faz necessária a restruturação dos cursos de formação inicial de professores da educação básica, incluindo não somente os conhecimentos da EJAI, mas também das outras modalidades de ensino existentes, de modo a garantir os conhecimentos essenciais aos futuros professores para que possam contribuir para a elevação do padrão de qualidade das escolas públicas brasileiras. Nesse sentido, os parâmetros estabelecidos pelas Diretrizes Curriculares Nacionais para a Formação Inicial e Continuada dos Profissionais do Magistério para a Educação Básica estabelecem que:

Art. $8^{\circ} \mathrm{O}(\mathrm{A})$ egresso(a) dos cursos de formação inicial em nível superior deverá, portanto, estar apto a: II - compreender o seu papel na formação dos estudantes da educação básica a partir de concepção ampla e contextualizada de ensino e processos de aprendizagem e 
desenvolvimento destes, incluindo aqueles que não tiveram oportunidade de escolarização na idade própria (BRASIL, 2015, p. 7).

Quanto às mudanças que devem acontecer na formação inicial dos educadores, Freitas (2014, p. 438) expõe que:

A unidade entre teoria e prática e entre educação e vida, em um caráter contínuo, é o objetivo a ser perseguido pelos cursos e programas de formação dos quadros do magistério em todas as licenciaturas. As mudanças recentes na organização da escola - ensino fundamental de nove anos e educação integral, ensino médio integrado - demandam novas formas curriculares nas licenciaturas e nos cursos de pedagogia que devem ser amplamente debatidas pelos educadores das universidades e pelos profissionais da educação básica.

Enquanto a formação inicial adequada aos anseios das especificidades existentes não vem acontecendo na maioria dos cursos de licenciatura, a formação continuada dos professores, embora desarticulada da formação inicial, é compreendida "como componente essencial da profissionalização inspirada nos diferentes saberes e na experiência docente, integrando-a ao cotidiano da instituição educativa, bem como ao projeto pedagógico da instituição de educação básica" (BRASIL, 2015, p. 5). Consoante definição das Diretrizes Curriculares Nacionais para a Formação Inicial e Continuada dos Profissionais do Magistério, essa formação continuada dar-se-á:

[...] pela oferta de atividades formativas e cursos de atualização, extensão, aperfeiçoamento, especialização, mestrado e doutorado que agreguem novos saberes e práticas, articulados às políticas e gestão da educação, à área de atuação do profissional e às instituições de educação básica, em suas diferentes etapas e modalidades da educação (BRASIL, 2015, p. 14).

Além disso, a meta 16 do atual PNE contempla a proposta de formar, em nível de pós-graduação, $50 \%$ dos professores da educação básica e garantir a todos os profissionais da educação básica formação continuada em sua área de atuação (BRASIL, 2014), enfatizando o aprimoramento da formação docente como indispensável à promoção de uma educação de qualidade para elevação do padrão de escolaridade básica no País. Diante disso, estabelece as seguintes estratégias para o alcance dessa meta:

16.1) realizar, em regime de colaboração, o planejamento estratégico para dimensionamento da demanda por formação continuada e fomentar a respectiva oferta por parte das instituições públicas de educação superior, de forma orgânica e articulada às políticas de formação dos Estados, do Distrito Federal e dos Municípios;

16.2) consolidar política nacional de formação de professores e professoras da educação básica, definindo diretrizes nacionais, áreas prioritárias, instituições formadoras e processos de certificação das atividades formativas;

16.3) expandir programa de composição de acervo de obras didáticas, paradidáticas e de literatura e de dicionários, e programa específico de acesso a bens culturais, incluindo obras e materiais produzidos em Libras e em Braille, sem prejuízo de outros, a serem disponibilizados para os professores e as professoras da rede pública de educação básica, favorecendo a construção do conhecimento e a valorização da cultura da investigação;

16.4) ampliar e consolidar portal eletrônico para subsidiar a atuação dos professores e das professoras da educação básica, disponibilizando gratuitamente materiais didáticos e pedagógicos suplementares, inclusive aqueles com formato acessível;

16.5) ampliar a oferta de bolsas de estudo para pós-graduação dos professores e das professoras e demais profissionais da educação básica;

16.6) fortalecer a formação dos professores e das professoras das escolas públicas de educação básica, por meio da implementação das ações do Plano Nacional do Livro e Leitura 
e da instituição de programa nacional de disponibilização de recursos para acesso a bens culturais pelo magistério público (BRASIL, 2014, p. 13).

De acordo com o disposto no PNE, o PEE/MA 2014-2024 objetiva implantar uma política estadual de formação e valorização dos profissionais da educação, propondo a formação continuada dos professores e a melhoria das suas condições de trabalho (MARANHÃO, 2014). Já no que se refere à EJAI, propõe erradicar o analfabetismo absoluto e reduzir a taxa de analfabetismo funcional, por meio da seguinte estratégia: "10.18) desenvolver e garantir políticas para os educadores e educandos da modalidade EJAI, visando ao aperfeiçoamento da prática pedagógica que possibilite a construção de novas estratégias de ensino e uso das tecnologias da informação" (MARANHÃO, 2014, p. 23).

Estabelecidas essas metas e estratégias de formação docente, pressupõe-se a existência de investimentos de natureza contábil para que os objetivos sejam alcançados dentro dos prazos estabelecidos nos planos educacionais. De acordo com Pereira e Lima (2016), o FUNDEB, fundo público que financia todas as etapas e modalidades da educação básica pública, é o recurso utilizado para financiar as ações de capacitação de professores e a aquisição de materiais didáticos e para garantir o alcance das metas propostas pelos atuais planos educacionais brasileiros, inclusive no que diz respeito à EJAI.

\section{SITUAÇÃO DA REDE DE ENSINO MARANHENSE}

Sobre as atuais condições da EJAI no Maranhão, os dados do Censo Escolar de 2015 revelam que existem 2.931 professores atuando na EJAI em 270 escolas de ensino fundamental e médio da Rede Pública Estadual do Maranhão². Com referência à formação continuada dos professores, em se tratando de pós-graduação, a tabela abaixo revela os seguintes dados:

Tabela 1 - Número de Professores da EJAI com Pós-graduação atuando na Rede Pública Estadual do Maranhão

\begin{tabular}{l|c}
\hline \multicolumn{1}{c|}{ Curso de Pós-graduação } & Quantidade de Professores \\
\hline Especialização & 1.237 \\
\hline Mestrado & 33 \\
\hline Doutorado & 7 \\
\hline
\end{tabular}

Fonte: Elaborada com base nos dados fornecidos pela Superintendência de Estatística da SEDUC-MA.

Verificamos que uma parcela superior à metade dos professores não possui pós-graduação. Assim, considerando o fato de a maioria dos professores trabalharem em três turnos e as dificuldades de acesso a cursos de pós-graduação gratuitos, a inserção dos professores nos programas de pós-graduação torna-se inviável. Essas condições revelam que os professores da educação básica dispõem de pouco tempo para continuar estudando e possuem raríssimas oportunidades para cursar uma pós-graduação gratuita.

Nos últimos anos, o Ministério da Educação (MEC), por meio da Secretaria de Educação Continuada, Alfabetização e Diversidade (SECADI), em parceria com as Universidades Federais e com a Universidade Aberta do Brasil, promoveu alguns Cursos de Especialização oportunizando acesso a conhecimentos, conteúdos, métodos, técnicas e recursos de ensino da EJAI. AUniversidade Estadual do Maranhão (UEMA) também ofereceu o Curso de Especialização em Educação de Jovens, Adultos e Idosos entre os anos de 2012 e 2014 e o Instituto Federal de Educação, Ciência e Tecnologia do Maranhão (IFMA) ofereceu o Curso de Especialização em Educação Profissional Integrada com a Educação Básica na Modalidade de Educação de Jovens e Adultos entre os anos de 2013 e 2015, oferecido na modalidade a distância aos profissionais que atuam em escolas públicas dos municípios de Barra do Corda, Caxias, Pinheiro e São Luís. De maneira contínua, o Instituto de Estudos Superiores do Maranhão - IESMA, instituição privada, oferece o Curso de Especialização em Educação de Jovens e Adultos.

Ademais, os professores contam com cursos presenciais realizados em outros estados ou cursos pagos realizados a distância. No entanto, os ganhos financeiros proporcionados aos

2 Informe Estatístico - Maranhão - 2015/Censo Escolar - SEDUC-MA - INEP - MEC. 
professores pós-graduados decorrentes desses investimentos são muito pequenos e assim os professores não se sentem estimulados a realizar uma pós-graduação paga ou gratuita em outros estados.

A falta de oportunidade de profissionalização e formação para professores tem um impacto negativo sobre a qualidade da oferta de aprendizagem e educação do segmento da EJAI (BRASIL, 2010). Com isso, a necessidade da formação continuada em nível de pós-graduação, prescrita nos planos educacionais, ganha destaque no campo da formação docente.

Quanto à formação continuada de curta duração, compreendida como as atividades formativas e cursos de atualização, extensão e aperfeiçoamento, o PNE 2014 prescreve a formação continuada dos professores em sua área de atuação, o que sugere a oferta de cursos específicos na área da EJAI. Conforme prescrevem as Diretrizes Curriculares Nacionais para a Formação Inicial e Continuada dos Profissionais do Magistério para a Educação Básica, deve ser assegurada:

VII - oferta de programas permanentes e regulares de formação e aperfeiçoamento profissional do magistério e a instituição de licença remunerada e formação em serviço, inclusive em nível de pós-graduação, de modo a atender às especificidades do exercício de suas atividades, bem como os objetivos das diferentes etapas e modalidades da educação básica (BRASIL, 2015, p. 16).

Para atender ao previsto nas Diretrizes Nacionais, nas metas e estratégias do PNE 2014 e do PEE/MA 2014, a SEDUC/MA, por meio da SUPEJA, vem realizando anualmente algumas ações de formação continuada para os professores que atuam na EJAI. Conforme a Técnica da SUPEJA ${ }^{3}$, que respondeu ao instrumento da pesquisa, uma equipe de profissionais da Supervisão realiza encontros mensais com os supervisores e professores das escolas de ensino fundamental e médio da rede. Os encontros obedecem a um planejamento por área, conforme indicado a seguir:

Tabela 2 - Áreas do Conhecimento para Formação Continuada dos Professores atuando no Ensino

Fundamental e Médio na modalidade EJAI da Rede Pública Estadual do Maranhão

\begin{tabular}{|l|l|}
\hline \multirow{2}{*}{$\begin{array}{l}\text { Áreas de Conhecimento } \\
\text { das } 1^{\mathrm{a}} \text { e } 2^{\mathrm{a}} \text { Etapas do Ensino Fundamental }\end{array}$} & Língua Portuguesa \\
\cline { 2 - 2 } & Matemática \\
\cline { 2 - 2 } $\begin{array}{l}\text { Áreas de Conhecimento } \\
\text { das } 3^{\mathrm{a}} \text { e } 4^{\mathrm{a}} \text { Etapas do Ensino Fundamental }\end{array}$ & Língua Portuguesa, Língua Estrangeira, Educação Física e Arte \\
\cline { 2 - 2 } & Matemática \\
\cline { 2 - 2 } & História, Geografia, Ciências, Ensino Religioso e Filosofia \\
\hline \multirow{2}{*}{$\begin{array}{l}\text { Áreas de Conhecimento } \\
\text { do Ensino Médio }\end{array}$} & $\begin{array}{l}\text { Linguagens (Língua Portuguesa, Língua Estrangeira Moderna - } \\
\text { Inglês e/ou Espanhol, Arte e Educação Física) }\end{array}$ \\
\cline { 2 - 2 } & Ciências da Natureza (Biologia, Física e Química) \\
\cline { 2 - 2 } & Ciências Humanas (História, Geografia, Sociologia e Filosofia) \\
\cline { 2 - 2 } & Matemática \\
\hline
\end{tabular}

Fonte: Elaborada com base nos dados fornecidos pela SUPEJA/SEDUC-MA.

Essas formações oportunizam momentos de discussões sobre a EJAI, bem como a apresentação de modelos de atividades para que os professores analisem a viabilidade de adaptá-las à realidade de suas escolas. Até o momento desta pesquisa, as formações tinham sido realizadas somente com os supervisores e professores que trabalham em escolas nos municípios de São Luís, São José de Ribamar, Paço do Lumiar e Raposa. Conforme relatou Técnica da SUPEJA4:

Essa iniciativa ainda não alcançou os interiores do Maranhão, somente existe um calendário anual de formação para a Unidade Regional de Educação (URE) de São Luís. Caso outras URE do estado solicitem uma formação, nós encaminhamos uma pequena equipe para formação no interior, ou mandamos o material por e-mail e a própria URE realiza a formação continuada dos professores daquela localidade.

Embora o FUNDEB, como mencionado anteriormente, possa ser utilizado para financiar ações de capacitação dos professores, nas quais se incluem as capacitações em EJAl, o que se percebe no Maranhão é que esse recurso não vem sendo aplicado com essa finalidade, ou seja, não são

3 Entrevista concedida em 16/12/2016.

4 Entrevista concedida em 16/12/2016. 
investidas no custeio da formação continuada dos professores. Conforme relatou a entrevistada ${ }^{5}$ : as próprias formações realizadas com os profissionais da EJAI ligados à Unidade Regional de Educação - URE de São Luís ocorrem por não terem custos para a SEDUC/MA.

Existem expectativas de que a Assessoria de Formação Inicial e Continuada, criada recentemente na SEDUC/MA, possa programar propostas mais eficazes de formação continuada aos professores de todo o estado, incluindo os da EJAI, dentro dos recursos legais estabelecidos. No entanto, essa Assessoria ainda não possui nenhuma ação prevista. Conforme relatou a Supervisora do Setor 6 : tudo ainda está sendo organizado em termos administrativos e procedimentais.

Além disso, deve-se considerar a desvantagem que existe na alocação de recursos e financiamentos para a EJAI sobre outras modalidades de ensino, o que pode continuar inviabilizando a implantação/implementação de uma proposta de formação continuada para os professores da EJAl em todo o estado. Assim sendo, não se podem criar tantas expectativas em relação às ações dessa Assessoria dedicada à formação docente criada pela SEDUC/MA.

O Fórum de Apoio à Formação Docente do Maranhão, que deveria estar em constante articulação com as IES e a SEDUC/MA, de modo a garantir a efetividade da formação continuada dos professores, mesmo tendo-se decorrido quase 8 anos desde sua criação pelo MEC, ainda não conseguiu sua implantação efetiva. Atualmente, ele está passando por um processo de revitalização, conforme relatou a Supervisora da Assessoria de Formação Inicial e Continuada da SEDUC/MA ${ }^{7}$ : em 2015, foram iniciadas as primeiras conversas, na qual ficou formada uma comissão que ainda passa por um processo de legalização dentro da Secretaria.

Acerca da articulação com os Fóruns Estaduais Permanentes de Apoio à Formação Docente, as Diretrizes Curriculares Nacionais para a Formação Inicial e Continuada dos Profissionais do Magistério para a Educação Básica estabelece que:

\footnotetext{
$\S 2^{\circ} \mathrm{A}$ instituição formadora, em efetiva articulação com o planejamento estratégico do Fórum Estadual de Apoio à Formação Docente e com os sistemas e redes de ensino e com as instituições de educação básica, definirá no seu projeto institucional as formas de desenvolvimento da formação continuada dos profissionais do magistério da educação básica, articulando-as às políticas de valorização a serem efetivadas pelos sistemas de ensino (BRASIL, 2015, p. 14).
}

No entanto, o Fórum Estadual do Maranhão que seria essa instância de articulação e proposição das formações inicial e continuada possui previsão para concluir sua organização somente em 2017, após adesão de novos integrantes, aprovação do regimento interno e definição do calendário de atividades, conforme relatou a Assessora da SEDUC/MA ${ }^{8}$.

\section{QUALIDADE DAS AULAS NA EJAI E A PERMANÊNCIA DA EXCLUSÃO SOCIAL NESSA MODALIDADE DE ENSINO}

Por meio da presente pesquisa, podemos identificar que a formação continuada dos professores da EJAI da rede pública estadual do Maranhão passa por um processo lento de implementação. As iniciativas são descontínuas, pois há escassez de recursos financeiros e carência de professores capacitados para ministrar os conteúdos das formações. Existe em todo o estado um elevado número de professores atuando subsidiados apenas pelos conhecimentos teóricos e metodológicos propiciados pela formação inicial sem as orientações específicas para trabalhar com jovens, adultos e idosos e que somente escolheram a EJAI por uma comodidade oferecida ao trabalhar no turno noturno, com a quantidade de alunos e a duração das aulas menores que em turmas do diurno.

Uma aula bem concebida é fundamental para produzir bons resultados na aprendizagem dos alunos, mesmo quando se trata de um segmento permeado por dificuldades como o da EJAI. De acordo com Scarpato (2004, p. 127), "[...] a aula significativa, que acrescenta sentido novo ao universo de conhecimentos dos alunos, é aquela que estabelece continuamente a relação entre a teoria estudada e a realidade vivida". O preparo dessa aula depende em parcela de um professor bem capacitado.

\footnotetext{
5 Entrevista concedida em 16/12/2016.

6 Entrevista concedida em 16/12/2016.

7 Entrevista concedida em 16/12/2016.

8 Entrevista concedida em 16/12/2016.
} 
Nesse sentido, as iniciativas não podem focar somente em uma pequena parcela dos educadores. Todos devem ser contemplados, dada à necessidade de um trabalho delicado com os alunos da EJAl, inclusive com os que moram nos municípios situados nas diferentes regiões do nosso estado, pois eles possuem especificidades que merecem ser tratadas com mais atenção durante a sua permanência na escola. São alunos que podem ser produtores rurais, ribeirinhos, indígenas ou remanescentes de quilombo e possuem uma realidade bastante diferente daquela das pessoas que moram na região metropolitana do nosso estado.

A EJAl embora criada dentro de uma perspectiva de superação da discriminação, objetivando viabilizar a inclusão dessa clientela, ainda não vem cumprindo efetivamente os seus preceitos. Percebemos, portanto, que os sujeitos da EJAI continuam sendo rotulados negativamente por não terem concluído os estudos na idade própria, por serem de variadas idades e ainda por disporem de realidades e contextos sociais diferentes. Conforme Brunel (2004), os sujeitos da EJAI constroem sua trajetória de escolarização básica fora dos padrões de ensino estabelecidos na modalidade regular. Dentro dessa perspectiva, Giovanetti (2006, p. 245) coloca que:

Os alunos da EJA, ao vivenciarem, pelo viés da exclusão social, o agravamento das formas de segregação - cultural, espacial, étnica, bem como das desigualdades econômicas -, experimentam, a cada dia, o abalo de seu sentimento de pertencimento social, o bloqueio de perspectivas de futuro social.

Diante da heterogeneidade que caracteriza esse segmento populacional, os professores não se sentem preparados para recebê-los na escola. As diversidades que compõem as turmas da EJAI têm oferecido muitos desafios aos professores. Observamos que alguns professores não dominam metodologias, técnicas de ensino, recursos didáticos específicos e novas tecnologias que possam contribuir para tornar as salas de aula da EJAI mais vivas e dinâmicas.

O PEE/MA2014 aponta a falta de professores com qualificação adequada para essa modalidade de ensino como um dos fatores que dificultam a permanência dos alunos na escola (MARANHÃO, 2014). Nas turmas de EJAI, cuja organização curricular no Ensino Médio é de dois anos de duração, um ano a menos que uma turma de ensino regular, alguns professores somente têm se preocupado em contemplar todo o conteúdo visto no ensino regular, não percebendo a impossibilidade de, em apenas dois anos, desenvolver todo um conjunto de conteúdos curriculares trabalhados nos três anos de Ensino Médio Regular, o que contribui para aprofundar as dificuldades de aprendizagem enfrentadas pelos educandos. Não existe preocupação em reduzir o conteúdo programático, dentro de uma perspectiva de dar significado à aprendizagem dos alunos.

A esse respeito, Marques e Zanata (2010) compreendem que existe uma concepção arraigada que privilegia uma educação conteudista não somente por parte dos professores e instituições escolares, mas também pelos próprios alunos. Para esses autores, existe uma visão de que "se o aluno não escreveu, não fez uma infinidade de atividades, o professor não cumpriu todo o conteúdo do programa a escola, o professor ou os alunos não estão cumprindo os objetos da escolarização" (MARQUES; ZANATA, 2010, p. 105).

Nesse sentido, percebemos que alguns professores estão presos à quantidade de conteúdos que devem abordar nas salas de aula, evidenciando a necessidade de investimentos na formação docente que contribuam para a construção de um novo olhar na atuação do professor da EJAI. Todavia, conforme aponta Rios (2011, p. 119), "nenhum Programa de Formação Continuada de Professores pode ter a garantia de uma mudança na práxis docente".

Outros fatores também estão provocando o esvaziamento das turmas de EJAI. Devemos considerar que os livros didáticos, embora específicos, não atendem às necessidades dos alunos, além de outros aspectos da escola que também não estão preparados para as características e demandas desse segmento. As próprias escolas utilizam como estratégia a matrícula de muitos alunos no começo do ano, já prevendo o abandono de parte deles até o final do ano letivo.

De acordo com Imbernón (2010, p. 21), "o professor e as condições de trabalho em que exerce sua profissão são o núcleo fundamental da inovação nas instituições educativas". Para esse autor, "a formação é um elemento importante de desenvolvimento profissional, mas não é o único e talvez não seja o decisivo" (IMBERNÓN, 2010, p. 46). A melhoria da formação docente e de vários outros 
fatores que também envolvem os educadores possui um papel importante no desenvolvimento de uma escola atrativa. A esse respeito o autor ainda acrescenta:

[...] a profissão docente desenvolve-se por diversos fatores: o salário, a demanda do mercado de trabalho, o clima de trabalho nas escolas em que é exercida, a promoção na profissão, as estruturas hierárquicas, a carreira docente etc. e, é claro, pela formação permanente que essa pessoa realiza ao longo de sua vida profissional (IMBERNÓN, 2010, p. 46).

Considerados os fatores que envolvem o docente e suas condições de trabalho, temos que contemplar também as situações externas à escola que envolvem diretamente o aluno jovem, adulto ou idoso que pretende iniciar ou retomar a vida escolar. Para muitos deles, não existem expectativas de conseguir um emprego após a conclusão dos estudos escolares, evidenciando que o estudo pautado na articulação entre formação de valores e formação profissional tem servido apenas para formação de um exército industrial de reserva (MARX, 1988), formando pessoas sem postos de trabalho. Fatores como, saúde, oferta de turmas principalmente no turno noturno e infraestrutura das escolas também devem ser observados.

Contudo, conforme prescrevem Sousa e Lima (2012), os principais nós da educação pública maranhense, centrados na busca pela qualidade, são a formação continuada de professores e a criação de uma carreira bem remunerada. Por meio da formação continuada dos professores, serão contempladas novas metodologias para que exerçam de forma consciente a sua profissão e assim contribuam para a melhoria da aprendizagem dos alunos.

Precisamos construir políticas de formação docente para o desenvolvimento do professor no âmbito da escola, o que requer a sua participação nos processos de discussão e elaboração das políticas educacionais. Nesse sentido, Sarmento (2012, p. 35) aponta que:

Não é demais insistir, porém, que a melhoria da qualidade da educação só acontecerá com a participação do professor. Apesar de se ter conquistado um piso salarial, ainda há dúvidas e resistências. O professor precisa ser ouvido, precisa acreditar na proposta. As políticas chegam à escola, mas não têm sido construídas com ela.

Não somente os professores, mas também os alunos precisam ser ouvidos para que as políticas atendam aos seus anseios e minimizem os problemas que surgem nas relações estabelecidas com o professor e a escola. Para Chauí (2016), os professores e estudantes são excluídos do discurso educacional, ainda que vivenciem essa experiência.

Somente depois que professores e estudantes sejam considerados nos aspectos políticos e legais, poderemos pensar as relações estabelecidas em sala de aula. Ambos são peças importantes do processo de ensino-aprendizagem e não devem ser considerados como coadjuvantes. A respeito das posturas do professor e do aluno da EJAI, Brunel (2004, p. 25) compreende que:

O professor que trabalha na EJA precisa estar aberto para um ouvir mais personalizado. Levar em conta a idade do aluno, sua situação financeira, seus sonhos, seus medos, sua posição de filho(a), de neto(a), de pai, de mãe, de esposo(a) para poder compreender a sua fala.

[...] ficou claro que eles estão precisando ser ouvidos e que, tão importante quanto a competência do professor ao transmitir o conteúdo em sala de aula, é a sua postura afetiva e de respeito, pois só assim o ambiente escolar será um lugar onde o aprender seja prazeroso, o saber importante e a escola tenha algum sentido nas suas vidas.

Dessa forma, percebemos que, enquanto a formação continuada não alcança todos os professores da EJAI, o que temos são profissionais que desconhecem as especificidades dessa modalidade que, em decorrência da inadequação dos métodos e procedimentos teóricos utilizados nas salas de aula, acabam contribuindo para a desistência de alguns alunos. Contudo, convém destacar que muitos docentes buscam superar as fragilidades de sua formação inicial e adotam estratégias próprias que contribuem para incentivar o aprendizado e elevar o estímulo do aluno em frequentar a escola.

Percebemos que, ao carregarem a "máscara social" de professor, os profissionais da educação criam estratégias de atuação e buscam informações a respeito dos indivíduos, definindo uma determinada situação, de forma que conseguem definir a melhor maneira de agir (GOFFMAN, 2009). 
Com uso de testes diagnósticos ou outras experiências adquiridas no dia a dia, os professores criam diversas técnicas para melhor conhecerem seus alunos no momento da aprendizagem, remediando a falta de formação continuada constatada na pesquisa.

\section{CONSIDERAÇÕES FINAIS}

A partir dos aspectos apresentados, inferimos que as ações de formação docente não esbarram somente na descontinuidade das políticas e recomendações teóricas propostas, mas também em questões orçamentárias relativas à falta de prioridade das ações governamentais que não veem a formação de professores como relevante, visto que a alternância no comando da política estatal provoca a interrupção dos projetos e programas iniciados pelo antecessor ou simplesmente mudam as estratégias sem qualquer aproveitamento ou aperfeiçoamento do que já havia sido iniciado.

As lacunas deixadas na formação inicial dos professores não são reparadas por meio da capacitação em serviço. No Maranhão, as ações de formação continuada programadas pelos órgãos gestores da educação pública estadual ainda estão longe de atingir todos os professores do estado, inviabilizando o adequado aperfeiçoamento dos profissionais que atuam na EJAI.

Percebemos que tais entraves se refletem em dificuldades enfrentadas pelos professores na sala de aula. Alguns adotam estratégias próprias e muitas vezes inadequadas para superar os obstáculos encontrados nas turmas. Além disso, eles são preparados em cursos de licenciatura para atuar no ensino regular e quando se deparam com o mercado profissional com poucas oportunidades, sujeitam-se a trabalhar em uma modalidade de ensino para a qual não possuem formação e conhecimentos de metodologias e técnicas educacionais adequadas a essa clientela.

AEJAI, de modo geral, deve ser priorizada pelo Estado para que todas as especificidades dessa modalidade sejam atendidas. É preciso então ampliar os percentuais dos recursos do FUNDEB para o financiamento dessa modalidade, antes que ela entre em decadência.

Os desafios educacionais a serem enfrentados no estado do Maranhão são imensos. No início de 2017, o Maranhão sinalizou um número considerável de escolas públicas fechadas no turno noturno, diminuindo desse modo o acesso do público prioritário dessa modalidade de ensino à escola. Faz-se necessário, portanto, ampliar as ações de capacitação de professores, incluindo metodologias específicas, voltadas principalmente para a inserção profissional dos alunos da EJAI e reestruturar as escolas fechadas, dotando-as de infraestrutura, materiais, equipamentos, recursos humanos e didáticos apropriados para atender aos alunos da EJAI.

Dessa forma, o direito à educação aos jovens, adultos e idosos será assegurado, não apenas com o acesso e a ampliação de vagas, mas também pela sua permanência em uma escola que ofereça um processo educativo comprometido com a inclusão efetiva desse sujeito. De acordo com Libâneo (2016, p. 59), "a escola pública continua sendo o melhor lugar e o melhor caminho para a luta política pela igualdade e inclusão social".

Nesse sentido, precisamos dinamizar o espaço escolar para que os alunos se sintam estimulados a iniciar seu processo de escolarização ou retomá-lo, mesmo que tardiamente. Os índices educacionais revelam que existe um percentual elevado de pessoas sem escolarização do Maranhão, logo encontramos demanda suficiente para ocupar as salas de EJAI que estão sendo fechadas. O esvaziamento dessas turmas tem ocorrido, principalmente, por causa da falta de significado que a instituição escolar oferece aos jovens, adultos e idosos, já que, para alguns deles, a "escola da vida" tem proporcionado conteúdos mais significativos do que a educação formal. 


\section{REFERÊNCIAS}

BRASIL. Constituição (1988). Constituição da República Federativa do Brasil. Brasília, DF: Senado Federal, 1988.

Decreto $n^{\circ} 6.253$, de 13 de novembro de 2007. Dispõe sobre o Fundo de Manutenção e Desenvolvimento da Educação Básica e de Valorização dos Profissionais da Educação - FUNDEB, regulamenta a Lei $n^{\circ} 11.494$, de 20 de junho de 2007, e dá outras providências. Diário Oficial da União, Brasília, DF, 14 nov. 2007a.

. Decreto $n^{\circ} 6.755$, de 29 de janeiro de 2009. Institui a Política Nacional de Formação de Profissionais do Magistério da Educação Básica, disciplina a atuação da Coordenação de Aperfeiçoamento de Pessoal de Nível Superior- CAPES no fomento a programas de formação inicial e continuada, e dá outras providências. Diário Oficial da União, Brasília, DF, 30 jan. 2009a.

. Decreto $n^{\circ} 8.752$, de 9 de maio de 2016. Dispõe sobre a política nacional de formação dos profissionais da educação básica. Diário Oficial da União. Brasília, DF, 10 maio 2016.

. Emenda Constitucional $n^{\circ} 53$, de 19 de de-

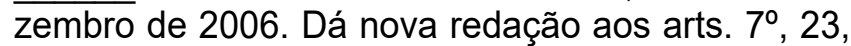
30, 206, 208, 211 e 212 da Constituição Federal e ao art. 60 do Ato das Disposições Constitucionais Transitórias. Diário Oficial da União. Brasília, DF, 20 dez. 2006.

Lei $n^{\circ} 9.394$, de 20 de dezembro de 1996. Estabelece as diretrizes e bases da educação nacional. Diário Oficial da União, Brasília, DF, 23 dez. 1996.

. Lei no 11.494, de 20 de junho de 2007. Regulamenta o Fundo de Manutenção e Desenvolvimento da Educação Básica e de Valorização dos Profissionais da Educação - FUNDEB, de que trata 0 art. 60 do Ato das Disposições Constitucionais Transitórias; altera a Lei $\mathrm{n}^{\circ} 10.195$, de 14 de fevereiro de 2001; revoga dispositivos das Leis nos 9.424 , de 24 de dezembro de 1996, 10.880, de 9 de junho de 2004, e 10.845, de 5 de março de 2004; e dá outras providências. Diário Oficial da União. Brasília, DF, 21 jun. 2007b.

. Lei $n^{\circ} 12.014$, de 06 de agosto de 2009. Altera 0 art. 61 da Lei $n^{\circ} 9.394$, de 20 de dezembro de 1996, com a finalidade de discriminar as categorias de trabalhadores que se devem considerar profissionais da educação. Diário Oficial da União. Brasília, DF, 07 ago. 2009b.
Lei $n^{0} 13.005$, de 25 de junho de 2014. Aprova o Plano Nacional de Educação - PNE e dá outras providências. Diário Oficial da União. Brasília, DF, 26 jun. 2014.

Portaria $n^{\circ} 883$, de 16 de setembro de 2009. Estabelece as diretrizes nacionais para o funcionamento dos Fóruns Estaduais Permanentes de Apoio à Formação Docente, criados pelo Decreto 6.755 , de 29 de janeiro de 2009. Diário Oficial da União, Brasília, DF, 17 set. 2009c. Seção 1, p. 26.

Resolução CNE/CEB $n^{0}$ 01, de 5 de julho de 2000. Estabelece as Diretrizes Curriculares Nacionais para a Educação de Jovens e Adultos. Diário Oficial da União, Brasília, DF, 06 jul. 2000.

Resolução CNE/CP n ${ }^{\circ} 2$, de $1^{\circ}$ de julho de 2015. Define as Diretrizes Curriculares Nacionais para a formação inicial em nível superior (cursos de licenciatura, cursos de formação pedagógica para graduados e cursos de segunda licenciatura) e para a formação continuada. Diário Oficial da União, Brasília, DF, 2 jul. 2015. Seção 1, p. 8-12.

Marco de Ação de Belém. Brasília, DF: UNESCO; MEC, 2010.

BRUNEL, C. Jovens cada vez mais jovens na educação de jovens e adultos. Porto Alegre: Mediação, 2004.

CARVALHO, M. P. As políticas para a educação de jovens e adultos nos governos Lula (2003-2010): incongruências do financiamento insuficiente. 2011. 349 f. Tese (Doutorado em Educação) - Universidade de São Paulo, São Paulo, 2011.

CHAUÍ, M. de S. Ideologia e educação. Educação e Pesquisa, São Paulo, v. 42, n. 1, p. 245-257, jan./ mar. 2016.

FREITAS, H. C. L. de. PNE e formação de professores: contradições e desafios. Revista Retratos da Escola, Brasília, DF, v. 8, n. 15, p. 427-446, jul./dez. 2014. Disponível em: <http//www.esforce.org.br>. Acesso em: 10 mar. 2017.

GIOVANETTI, M. A. G. de C. A formação de educadores de EJA: o legado da educação popular. In: SOARES, L.; GIOVANETTI, M. A. G. de C.; GOMES, N. L. (Org.). Diálogos na educação de jovens e adultos. 2. ed. Belo Horizonte: Autêntica, 2006.

GOFFMAN, E. A representação do eu na vida cotidiana. 17. ed. Petrópolis: Vozes, 2009. 
GUERRA, A.; POCHMANN, M.; SILVA, R. A. Atlas da exclusão social no Brasil: dez anos depois. São Paulo: Cortez, 2014.

IMBERNÓN, F. Formação docente e profissional: formar-se para a mudança e a incerteza. 8. ed. São Paulo: Cortez, 2010.

LIBÂNEO, J. C. Políticas educacionais no Brasil: desfiguramento da escola e do conhecimento escolar. Cadernos de Pesquisa, São Paulo, v. 46, n. 159, p. 38-62, jan./mar. 2016.

MARANHÃO. Lei $n^{0} 10.099$, de 11 de junho de 2014. Aprova o Plano Estadual de Educação (PEE) do Estado do Maranhão e dá outras providências. Diário Oficial do Poder Executivo, São Luís, 11 jun. 2014.

MARQUES, A. F.; ZANATA, E. M. Como estou me tornando um professor? In: CAMARGO, M. R. R. M. de; FURLANETTI, M. P. de F. R. (Org.). Educação de pessoas jovens e adultas: múltiplas faces de um projeto educacional: aportes teóricos, práticas de formação, contextos produzidos. São Paulo: UNESP, 2010.

MARX, K. O capital. 3. ed. São Paulo: Nova Cultural, 1988. v. 2.

OSTERNE, M. do S. F. Atualidades da "questão social", da justiça social e da gestão de políticas públicas. In: MACAMBIRA, J.; ANDRADE, F. B. (Org.). Estado e politicas sociais: fundamentos e experiências. Fortaleza: IDT; UECE, 2014.
PEREIRA, D. R.; LIMA, F. das C. S. A educação de jovens e adultos nos instrumentos jurídicos normativos. In: ENCONTRO DE EDUCADORES PESQUISAS E EXPERIÊNCIAS, 7., 2016, São Luis. Anais... São Luis: Universidade Federal do Maranhão, 2016. $1 \mathrm{CD}$.

PEREIRA, J. E. D. Formação de professores: pesquisas, representações e poder. 2. ed. Belo Horizonte: Autêntica, 2006.

RIOS, C. M. A. A educação de jovens e adultos no contexto contemporâneo da formação continuada de professores e das tecnologias da informação e comunicação. Salvador: EDUNEB, 2011.

SARMENTO, D. C. Educação: federalismo e qualidade. In: Educação e qualidade: sistemas educacionais em construção. Juiz de Fora, MG: Ed. UFRJ, 2012. p. 9-38.

SCARPATO, M. Os procedimentos de ensino fazem a aula acontecer. São Paulo: Avercamp, 2004.

SOARES, L. Do direito à educação à formação do educador de jovens e adultos. In: SOARES, L.; GIOVANETTI, M. A. G. de C.; GOMES, N. L. Diálogos na educação de jovens e adultos. 2. ed. Belo Horizonte: Autêntica, 2006.

SOUSA, J. U. P.; LIMA, F. das C. S. A educação no planejamento público do estado do Maranhão: das aspirações sociais às decisões. In: LIMA, F. das $C$. S.; LIMA, L. M.; CARDOZO, M. J. P. B. (Org.). Políticas educacionais e gestão escolar. os desafios da democratização. São Luís: EDUFMA, 2012. 